This item was submitted to Loughborough's Research Repository by the author.

Items in Figshare are protected by copyright, with all rights reserved, unless otherwise indicated.

\title{
Time-Resolved Particle Image Velocimetry of dynamic interactions between hydrogen-enriched methane/air premixed flames and toroidal vortex structures
}

\section{PLEASE CITE THE PUBLISHED VERSION}

http://dx.doi.org/10.1016/j.ijhydene.2012.08.061

\section{PUBLISHER}

(c) Hydrogen Energy Publications, LLC. Published by Elsevier Ltd.

\section{VERSION}

AM (Accepted Manuscript)

\section{LICENCE}

CC BY-NC-ND 4.0

\section{REPOSITORY RECORD}

Di Sarli, Valeria, Almerinda Di Benedetto, Edward J. Long, and Graham K. Hargrave. 2019. "Time-resolved Particle Image Velocimetry of Dynamic Interactions Between Hydrogen-enriched Methane/air Premixed Flames and Toroidal Vortex Structures". figshare. https://hdl.handle.net/2134/13439. 
This item was submitted to Loughborough's Institutional Repository (https://dspace.lboro.ac.uk/) by the author and is made available under the following Creative Commons Licence conditions.

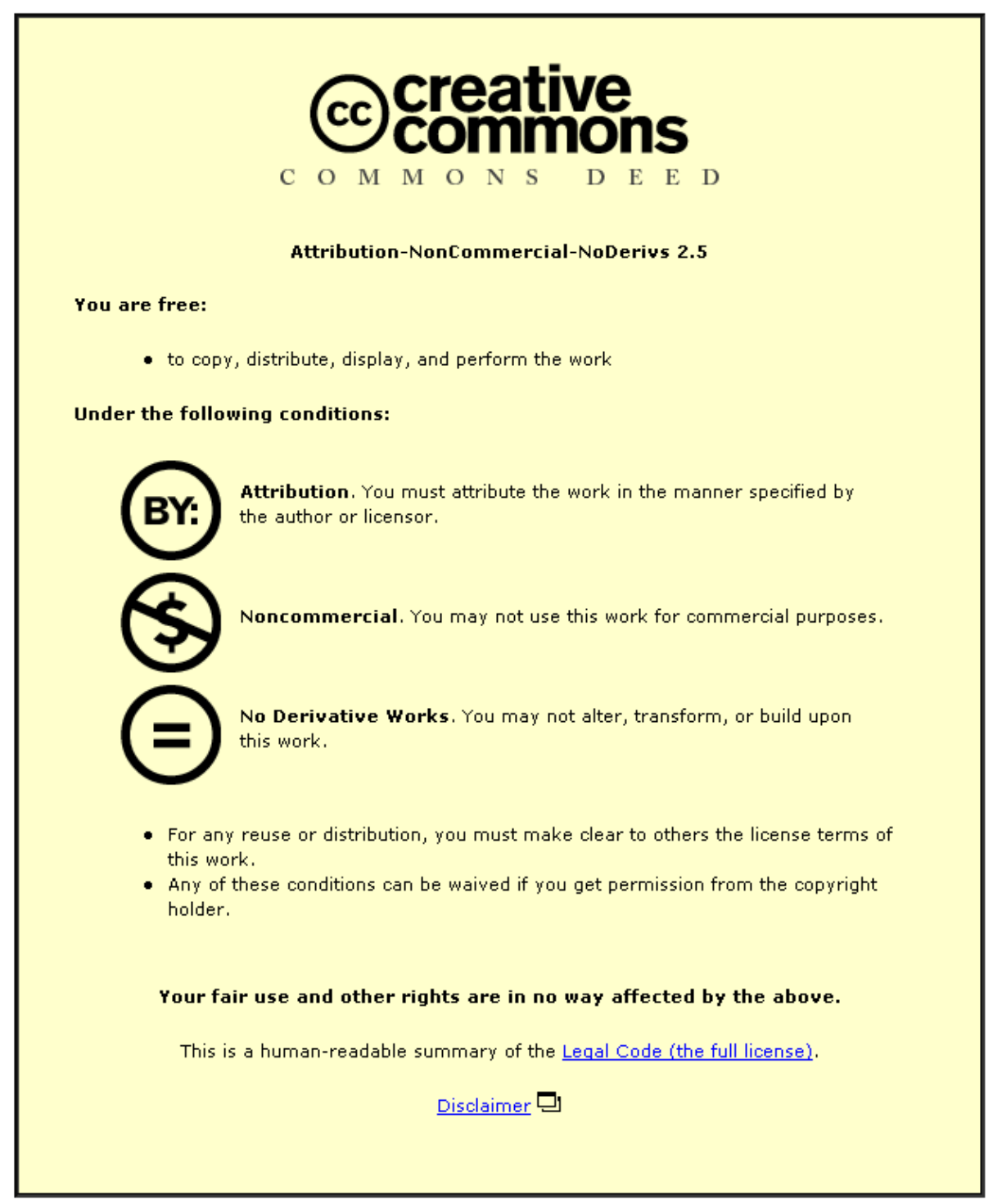

For the full text of this licence, please go to: http://creativecommons.org/licenses/by-nc-nd/2.5/ 


\title{
Time-Resolved Particle Image Velocimetry of Dynamic
}

\section{Interactions Between Hydrogen-Enriched Methane/Air}

\section{Premixed Flames and Toroidal Vortex Structures}

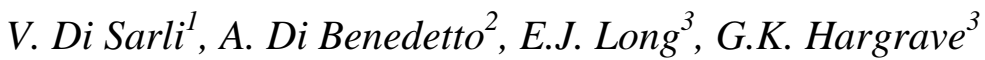 \\ ${ }^{1}$ Istituto di Ricerche sulla Combustione - Consiglio Nazionale delle Ricerche (IRC-CNR), \\ Via Diocleziano 328, 80124, Napoli, IT \\ ${ }^{2}$ Dipartimento di Ingegneria Chimica, Università degli Studi di Napoli Federico II, \\ Piazzale Tecchio 80, 80125, Napoli, IT \\ ${ }^{3}$ Wolfson School of Mechanical and Manufacturing Engineering, Loughborough \\ University, Loughborough, Leicestershire, LE11 3TU, UK
}

Corresponding author:

Dr. Valeria Di Sarli

Phone: +39 0817622673; Fax: +39 0817622915; E-mail: valeria.disarli@irc.cnr.it

Co-authors:

Prof. Almerinda Di Benedetto, Email: almerinda.dibenedetto@unina.it

Dr. Edward J. Long, Email: E.J.Long@lboro.ac.uk

Prof. Graham K. Hargrave, Email: G.K.Hargrave@lboro.ac.uk 


\title{
Time-Resolved Particle Image Velocimetry of Dynamic
}

\section{Interactions Between Hydrogen-Enriched Methane/Air}

\section{Premixed Flames and Toroidal Vortex Structures}

\author{
V. Di Sarli ${ }^{1, *}$, A. Di Benedetto ${ }^{2}$, E.J. Long ${ }^{3}$, G.K. Hargrave ${ }^{3}$ \\ ${ }^{1}$ Istituto di Ricerche sulla Combustione - Consiglio Nazionale delle Ricerche (IRC-CNR), \\ Via Diocleziano 328, 80124, Napoli, IT \\ ${ }^{2}$ Dipartimento di Ingegneria Chimica, Università degli Studi di Napoli Federico II, \\ Piazzale Tecchio 80, 80125, Napoli, IT \\ ${ }^{3}$ Wolfson School of Mechanical and Manufacturing Engineering, Loughborough \\ University, Loughborough, Leicestershire, LE11 3TU, UK
}

\begin{abstract}
Time-Resolved Particle Image Velocimetry was used to study transient interactions between hydrogen-enriched methane/air premixed flames and toroidal vortex structures. Lean and stoichiometric mixtures with hydrogen mole fraction in the fuel (hydrogen plus methane), $x_{\mathrm{H} 2}$, varying in the range of $0-0.5$ were investigated.

Results have shown that the hydrogen presence affects the flow field both quantitatively (increase of the velocity of the main toroidal vortex) and qualitatively (generation of different sub-vortices within the main vortex), enhancing the intensity of the interaction. Regardless of the mixture stoichiometry, the hydrogen substitution to methane leads to a transition from a regime in which the vortex only wrinkles the flame front $\left(x_{\mathrm{H} 2}<0.2\right)$ to a

\footnotetext{
* Corresponding author. Phone: +39 0817622673; Fax: +39 0817622915;

E-mail address: valeria.disarli@irc.cnr.it
} 
more vigorous regime in which the interaction almost results in the separation of small flame pockets from the main front $\left(x_{H 2}>0.2\right)$. This transition was characterised in terms of time histories of flame surface area and burning rate.

Keywords: Hydrogen-Enrichment; Premixed Combustion; Unsteady Propagation; FlameVortex Interaction; Time-Resolved Particle Image Velocimetry; Combustion Regimes. 


\section{Introduction}

Hydrogen-enrichment appears to be a promising methodology for solving problems encountered during turbulent combustion of natural gas/air mixtures (flame extinction, combustion oscillations, lower power output, etc.) in both stationary [1] and mobile [2] applications.

Hydrogen and methane (the main constituent of natural gas) are significantly different fuels. Hydrogen produces higher adiabatic flame temperature (at stoichiometric conditions in air) than methane (2380 K versus $2220 \mathrm{~K}$ ), and has higher maximum adiabatic laminar burning velocity (320 cm/s versus $40 \mathrm{~cm} / \mathrm{s}$ for methane) [3]. Differences also concern transport properties: hydrogen exhibits higher molecular diffusion coefficient in air $\left(\sim 0.6 \mathrm{~cm}^{2} / \mathrm{s}\right)$ than methane (and oxygen) $\left(\sim 0.2 \mathrm{~cm}^{2} / \mathrm{s}\right)$, and lower Lewis number (i.e., ratio of thermal diffusivity to mass diffusivity) ( $~ 0.3$ versus $\sim 1$ for methane) [4]. Experimental and computational studies performed in simplified flow configurations (freely and spherically propagating flames, counterflow flames, Bunsen-type and slot burners) have shown that the hydrogen addition to methane increases the laminar burning velocity (i.e., the flame reactivity) [5-10], the resistance to strain extinction [1,5-7,9,11] and the flame front wrinkling (i.e., the flame surface area) [4,7], thus enhancing robustness and stability of the flame. These positive effects have been attributed to the increase in both flame temperature (thermal effects) and supply of active radicals (chemical effects). Also, hydrogen-induced non-equidiffusive effects (i.e., non-unity Lewis number and preferential diffusion) have been invoked for lean flames [4-7,11].

The role of hydrogen is quite well understood in terms of flame reactivity and response to stretch and curvature. However, the practical use of hydrogen-methane blends is yet 
limited. This is due to a lack in the knowledge about the mechanisms of dynamic interaction between hydrogen-enriched flames and turbulent flow fields [12], which control premixed flame propagation in combustors, industrial burners and engines [see, e.g., 13-17] as well as in gas explosions [see, e.g., 18,19].

The behaviour of a premixed flame moving through a turbulent flow field is strongly affected by the nature of the vortex structures present along the flame path [20]. The flame-vortex interaction may lead the flame to propagate according to different turbulent combustion regimes, which are dependent on both size and velocity of the vortices. On the other hand, it is difficult to characterise such an interaction in practical systems, given the complexity of the turbulent structures generated.

The work presented in this paper fits into this framework by looking at how the hydrogen addition to methane affects the interaction between premixed flames and simple toroidal vortices generated, in a controlled manner, at the wake of an orifice. As demonstrated for pure methane flames [21-24], such simple and controllable vortex structures provide different benefits over truly turbulent fields when fundamental investigation into flameturbulence interactions is performed.

The research used Time-Resolved Particle Image Velocimetry with micro-sized particles of olive oil as the seeding material. This enabled not only recording of the temporal development of the velocity field (ahead of the flame front), but also identification of the position of the front (through the consumption of the olive oil droplets by the flame) and, thus, quantification of its evolution in terms of time histories of flame surface area and burning rate.

In the following, after a description of the experimental arrangement, results are presented and discussed as obtained for lean (equivalence ratio, $\phi$, equal to 0.8) and stoichiometric 
mixtures with hydrogen mole fraction in the fuel (hydrogen plus methane), $x_{H 2}$, varying in the range of 0-0.5. 


\section{Experimental Arrangement}

The combustion bomb and the Time-Resolved Particle Image Velocimetry (TRPIV) technique used in this investigation have been described previously [21,22].

Briefly, the combustion bomb consisted of a small cylindrical pre-chamber linked to a much larger main chamber via an orifice (Figure 1). The main chamber was constructed from aluminium panels fitted with borosilicate glass windows to enable optical access. Premixed charges of fuel (hydrogen plus methane) and air were ignited (from rest) at the centre of the bottom face of the pre-chamber. Experiments were run for lean (equivalence ratio, $\phi$, equal to 0.8 ) and stoichiometric mixtures with hydrogen mole fraction in the fuel, $x_{H 2}$, varying in the range of 0-0.5. After ignition, the propagation of the flame front set in motion unburned gas ahead of it through the orifice. The interaction of this movement with the downstream static charge resulted in a shear layer at the orifice exit and, thus, shedding of a toroidal vortex into the main chamber. As the flame front progressed through the charge, it interacted with this vortex. The flame-vortex interaction was highly controllable and repeatable in nature.

The TRPIV system (Figure 2) consisted of a Photron APX-RS CMOS high speed camera (pixel resolution of 1024 x 1024) synchronised with a New Wave Research Pegasus (Duel Cavity, Diode Pumped) Nd-YLF laser in order to operate in a two frame PIV mode (recording frame rate of 3000 frames per second, i.e., $1500 \mathrm{~Hz}$ PIV). Particles of $1 \mu \mathrm{m}$ olive oil were introduced into the charge to act as the tracing material. A 2D crosscorrelation FFT algorithm incorporating a multi-pass approach was used to analyse corresponding particle image pairs. The initial pass of the routine analysed the images using 32 by 32 pixel interrogation regions, the final pass used interrogation regions of 
16 x 16 pixels. A 3-point Gaussian peak search algorithm was used to calculate sub-pixel displacement and a $50 \%$ Nyquist overlap of the regions was incorporated. The small interrogation region was employed to reduce the impact of high velocity gradients within the vortex region on the results.

With TRPIV, data were recorded from a single combustion event. In addition to the measurement of the unburned gas velocity, the raw TRPIV images were used to follow the temporal development of the flame front (identified through the consumption of the olive oil droplets by the front itself). From these images, data on the length of flame front and the area of burned gas were also obtained. To achieve this, a MATLAB program was written to analyse the two-dimensional section of the combustion event, identifying the region of burned gas and its interface to the unburned gas at the flame edge. The basis of the MATLAB program is an examination of each pixel and its local surroundings to determine if it exists within the seeded region (unburned) or where the seeding has been consumed (burned). Once the flame boundary has been established, the program calculates the total length of the flame present in the image region and the burned area. Such data will be presented in Section 3, adopting the three-dimensional nomenclature, as flame surface area, $A_{F}$, and volume of burned gas, $V_{B}$, (per unit depth in the third direction) respectively. 


\section{Results and Discussion}

\subsection{Flame Front Development}

In Figures 3 and 4, the time sequences of raw images of the laser illuminated particles gathered using the TRPIV technique are shown for lean (equivalence ratio, $\phi$, equal to 0.8 ) (Figure 3) and stoichiometric (Figure 4) mixtures with hydrogen mole fraction in the fuel (hydrogen plus methane), $x_{\mathrm{H} 2}$, varying in the range of $0-0.5$. These figures provide valuable information about the dynamics of the flame-flow interaction.

As the flame propagates through the charge, the dark area (corresponding to the burned gas area) increases and the presence of hydrogen enhances its rate of growth. The time at which the flame has completely consumed the mixture in the vortex decreases with increasing hydrogen content in the fuel, ranging from around $4 \mathrm{~ms}$ for $x_{H 2}=0$ to around $2 \mathrm{~ms}$ for $x_{H 2}=0.5$.

Regardless of the mixture stoichiometry and the fuel composition, Figures 3 and 4 show the same mode of interaction: the flame propagates around the toroidal vortex formed at the orifice wake, until the vortex is fully burned. The flame exiting the orifice appears to be substantially flat. During the interaction with the flow, a progressive increase in flame front wrinkling can be observed. For the case of pure methane, the toroidal vortex is very smooth with any perturbations within the main vortex roll-up being very weak. The interaction with this (main) vortex wrinkles the flame front, leaving the front structure essentially unperturbed. On the contrary, in the presence of hydrogen, due to the greater velocities and shear developed, sub-vortices are generated within the main toroidal vortex. The formation of these small structures is particularly evident for stoichiometric mixtures. As shown in the first images of the time sequences, they appear as slightly darker spots 
describing a pinwheel around the main vortex due to the tracer particles being spun out from their centres (not due to any combustion). The flame simultaneously interacts with the main vortex and the sub-vortices that distribute themselves along the front; this increases the degree of wrinkling. Furthermore, in addition to wrinkling the flame, the flame-flow interaction can be seen to locally break the continuity of the front. This breakup process leads to the formation of openings in the main front and almost results in the separation of small flame pockets. As a result of this break-up process, the flame surface area is significantly increased.

\subsection{Velocity Vector Fields}

In Figures 5 and 6, the velocity vector maps are presented as measured by TRPIV for lean (Figure 5) and stoichiometric (Figure 6) mixtures with $x_{H 2}$ equal to (a) 0, (b) 0.2, (c) 0.4 and (d) 0.5. The burned gas regions correspond to the regions containing no velocity vectors.

The PIV velocity fields show qualitative similarities. A difference is the absolute value of the flow velocity that increases in going from lean to stoichiometric conditions and, for each equivalence ratio, with increasing $x_{H 2}$. As shown in Table 1 , for both lean and stoichiometric mixtures, the value of the maximum rotational velocity of the vortex core, $u_{\theta, \max }$, almost doubles itself when $x_{H 2}$ varies from 0 (pure methane) to 0.5 . On the contrary, the vortex core diameters remain near identical $(\sim 6 \mathrm{~mm})$.

The laminar burning velocity, $S_{L}$, dictates the flame speed and, thus, the flow velocity exiting the orifice (upstream of the orifice, the flame propagation is substantially laminar). We ran simulations to compute the laminar burning velocity. To this end, we used the Sandia PREMIX module [25] of the CHEMKIN package (version 10101). The module was coupled to the GRI-Mech (version 3.0) [26] reaction mechanism. The same model 
was used in previous works for $\mathrm{CH}_{4} / \mathrm{H}_{2} /$ air [8], $\mathrm{CH}_{4} / \mathrm{O}_{2} / \mathrm{N}_{2} / \mathrm{CO}_{2}$ and $\mathrm{H}_{2} / \mathrm{O}_{2} / \mathrm{N}_{2} / \mathrm{CO}_{2}$ [27] mixtures. A satisfactory agreement between model predictions and experimental data was found.

Results from CHEMKIN computations are given in Table 1. The increase of $S_{L}$ with $\phi$ and $x_{H 2}$ leads to the increase in flow velocity seen in the TRPIV data. This increase in gas velocity exiting the pre-chamber greatly increases the vorticity of the main toroidal vortex. In addition, the increased velocities and shear developed in the flow with the increasing equivalence ratio and hydrogen content enhance the formation of small sub-vortices previously described in Sub-Section 3.1. These small vortices are only visible in the PIV data as slight oscillations in the velocity field surrounding the main vortex core, a result of the small rotations being embedded within the main vortex recirculation.

\subsection{Flame Surface Area and Burning Rate}

In Figures 7 and 8, the time evolution of the flame surface area, $A_{F}$, is shown as extracted from the raw TRPIV images for lean (Figure 7) and stoichiometric (Figure 8) mixtures with different fuel compositions.

Initially, a phase of growth of the flame area is observed. The rate of growth increases with $x_{H 2}$ (the initial slopes for the flame area curves of Figures 7 and 8 are given in Table 2). After a maximum has been reached, the flame area decreases. This decrease is due to the process of roll-up of the flame on itself that is accompanied by the mutual annihilation of the fronts in the zones of contact and merging (Figures 3 and 4).

As previously discussed, the hydrogen presence increases the degree of flame wrinkling and also promotes the creation of small flame pockets almost separated from the main front. Wrinkling and pocket formation contribute to an increase in the flame surface area. On the other hand, as $x_{H_{2}}$ increases, the time needed for a complete roll-up of the flame 
decreases and the duration of the growth phase for the flame area decreases as well. Therefore, the peak value of the flame area does not increase with $x_{H 2}$. The maximum peak value is found at $x_{H 2}=0.2$ and corresponds to around $0.13 \mathrm{~m}$ for both equivalence ratios.

Table 2 also shows that, at $x_{H 2}=0.5$, the stoichiometric mixture exhibits lower initial slope than the lean mixture. In the stoichiometric case, the flame-vortex interaction has probably become too fast and, thus, less effective in increasing the flame area.

In Figures 7 and 8, the time trends of the burning rate are also presented. The burning rate, $r$, was estimated from the time evolution of the volume of burned gas within the TRPIV measurement region, $V_{B}$, as:

$$
r=\rho_{B} \frac{d V_{B}}{d t}
$$

where the burned gas density, $\rho_{B}$, was computed using the chemical equilibrium program Gaseq (www.c.morley.dsl.pipex.com) [28]. All trends exhibit a maximum; the peak value of the burning rate increases with increasing $x_{H 2}$.

It is interesting to note from Figures 7 and 8 that the hydrogen presence produces a better burning quality. This allows a synchronisation to be established between the time histories of the burning rate and the flame area $\left(x_{H 2}=0.4\right.$ and 0.5$)$. Furthermore, for $x_{H 2}=0.5$, the burning quality is also improved during the interaction (region between the dashed lines), as demonstrated by the fact that the burning rate increases more rapidly relative to the flame area. 


\subsection{Regimes of Flame-Vortex Interaction}

The behaviour of a premixed flame propagating through a turbulent flow field and, thus, the combustion regime experienced by the flame are strictly dependent on both size and velocity (i.e., strength) of the vortex structures encountered. In order to compare the flame-flow interactions observed in this study with other investigations, the spectral diagram proposed by Vasudeo et al. [29] for flame-vortex interaction was used. This

diagram is shown in Figure 9. It was obtained by using Direct Numerical Simulation (DNS) of interactions between a post-ignition (expanding) flame kernel and a counterrotating vortex pair. DNS computations were implemented in the simplified axisymmetric configuration also schematised in the figure that has similarities to the one in this investigation. Vasudeo et al. [29] quantify five distinct regimes of interaction for their physical arrangement in terms of two key parameters, evaluated at the beginning of the interaction. These parameters are the ratio of the vortex radius to the flame kernel radius ( $x$-axis), $R_{v} / R_{f}$, and the ratio of the maximum vortex rotational velocity to the laminar burning velocity ( $y$-axis), $u_{\theta, \max } / S_{L}$. The five regimes are (1) the laminar kernel regime, (2) the wrinkled kernel regime, (3) the breakthrough regime, (4) the global extinction regime and (5) the regeneration after global extinction (RGE) regime. Increasing the vortex size and velocity leads to a gradual transition through regimes 1-4. In the laminar kernel regime, the vortex is too small and/or weak and, thus, the structure and dynamics of the flame kernel are not affected by the interaction. In the wrinkled kernel regime, the flame front is wrinkled and distorted during the interaction with the vortex. In the breakthrough regime, the vortex is strong enough to break the continuity of the flame kernel. In particular, the vortex produces the splitting of the kernel into two kernels, which may eventually connect with each other, giving rise to a single deformed kernel. In the global 
extinction regime, the global straining of the flame kernel causes its extinction. Finally, in the RGE regime, reignition happens after most of the initial kernel has been extinguished because of intense straining.

The values of $R_{v}$ and $u_{\theta, \max }$ from these experiments, extracted from the PIV measurements of the velocity fields induced in the orifice wake at the onset of the interaction between the expanding flame and the toroidal vortex, were entered into the diagram of Figure 9 (stars represent points of lean mixtures; rectangles represent points of stoichiometric mixtures). In the same manner as Vasudeo et al. [29], $R_{v}(31.5 \mathrm{~mm})$ was obtained by summing the distance between the centre of the vortex and the axis of the chamber $(28.5 \mathrm{~mm}$, see Figure 1) and the vortex radius (3 mm). The dimensionless $R_{v} / R_{f}$ and $u_{\theta, \max } / S_{L}$ ratios were computed setting the flame radius, $R_{f}$, equal to the orifice radius $(15 \mathrm{~mm}$ ) and the laminar burning velocity, $S_{L}$, equal to the values reported in Table 1 (CHEMKIN computations). The $u_{\theta, \max } / S_{L}$ ratio increases with increasing $x_{H 2}$.

For the case of pure methane, the flame-vortex interaction sits on the spectral diagram near the border between the wrinkled kernel and breakthrough regimes. This position on the diagram is largely supported by Figures 3 and 4, where the vortex can be seen to substantially alter the overall shape of the flame front, but only slightly perturb the front structure.

The intensity of the flame-vortex interaction increases with increasing hydrogen mole fraction in the fuel, as a direct result of a self-reinforcing mechanism. That is, the higher reactivity of the hydrogen-enriched mixtures produces faster flame propagation upstream of the orifice and, thus, higher rotational velocity for the vortices generated at the orifice wake. This, in turn, leads to further increase in the burning rate resulting from the interaction. 
As $x_{H 2}$ is increased, the points move away from the border to enter the region of the breakthrough regime. Although, in these experiments, the flame is co-propagating with the vortex instead of counter-propagating (as in the configuration simulated by Vasudeo et al. [29]), a similar trend towards break-up of the flame front can still be seen in the results (Figures 3 and 4). In the presence of hydrogen, the vortex structures locally disrupt the continuity of the front, causing the creation of reaction zones that are only narrowly linked together. However, full breakthrough does not occur in these experiments as the flame is drawn into the toroidal vortex instead of the flame being separated by vortex ring. 


\section{Summary and Conclusions}

An experimental study has been carried out to investigate the transient interactions that occur between hydrogen-enriched methane/air premixed flame fronts and toroidal vortex structures. Interactions were generated, in a controlled manner, within the wake of a circular orifice. Lean (equivalence ratio equal to 0.8 ) and stoichiometric mixtures with hydrogen mole fraction in the fuel (hydrogen plus methane), $x_{H 2}$, varying in the range of 0-0.5 were investigated by means of Time-Resolved Particle Image Velocimetry. Microsized particles of olive oil were used as the seeding material. This enabled not only recording of the temporal development of the velocity field (ahead of the flame front), but also identification of the position of the front (through the consumption of the olive oil droplets by the flame) and, thus, characterisation of its evolution in terms of time histories of flame surface area and burning rate. The regimes of flame-vortex interaction were quantified using the spectral diagram proposed by Vasudeo et al. [29].

The following main conclusions can be drawn from the results obtained:

1) The intensity of the flame-vortex interaction increases with increasing hydrogen mole fraction in the fuel, as a direct result of a self-reinforcing mechanism. That is, the higher reactivity of the hydrogen-enriched mixtures produces faster flame propagation upstream of the orifice and, thus, higher rotational velocity for the vortices generated at the orifice wake. This, in turn, leads to further increase in the burning rate resulting from the interaction.

2) The hydrogen presence affects the flow field not only in quantitative terms, but also in qualitative terms. As $x_{H_{2}}$ increases, the velocity of the toroidal vortex increases. In addition, the greater velocities and shear developed cause sub-vortices 
to be generated within the main toroidal structure (especially for stoichiometric propagation). The flame simultaneously interacts with the main vortex and the subvortices; this increases the intensity of the interaction.

3) The hydrogen substitution to methane leads to a progressive transition from a regime in which the vortex only wrinkles the flame front (wrinkled regime, $\left.x_{H 2}<0.2\right)$ to a more vigorous regime in which the vortex locally breaks the continuity of the front, causing the creation of reaction zones that are nearly detached from the main front (breakthrough regime, $x_{H 2}>0.2$ ).

4) The rate of growth of the flame surface area increases with increasing $x_{H 2}$. Furthermore, the hydrogen-enrichment results in a better burning quality that allows a synchronisation to be established between the time histories of the flame surface area and the burning rate $\left(x_{H 2}=0.4\right.$ and 0.5$)$. During the interaction, an improvement of the burning quality has also been found $\left(x_{\mathrm{H} 2}=0.5\right)$.

This work represents a first step in the direction for investigating the interaction of hydrogen-enriched premixed flames with truly turbulent flow fields. The experimental data produced will be used for validation of a Large Eddy Simulation (LES) model of dynamic flame-vortex interactions in a future work. 


\section{References}

[1] Schefer RW, Wicksall DM, Agrawal AK. Combustion of hydrogen-enriched methane in a lean premixed swirl-stabilized burner. Proceedings of the Combustion Institute 2002;29:843-51.

[2] Bauer CG, Forest TW. Effect of hydrogen addition on the performance of methanefueled vehicles. Part I: effect on S.I. engine performance. International Journal of Hydrogen Energy 2001;26:55-70.

[3] Glassman I. Combustion. 3rd ed. San Diego (California): Academic Press; 1996.

[4] Hawkes ER, Chen JH. Direct numerical simulation of hydrogen-enriched lean premixed methane-air flames. Combustion and Flame 2004;138:242-58.

[5] Ren J-Y, Qin W, Egolfopoulos FN, Tsotsis TT. Strain-rate effects on hydrogenenhanced lean premixed combustion. International Journal of Hydrogen Energy 2001;124:717-20.

[6] Halter F, Chauveau C, Djebaïli-Chaumeix N, Gökalp I. Characterization of the effects of pressure and hydrogen concentration on laminar burning velocities of methanehydrogen-air mixtures. Proceedings of the Combustion Institute 2005;30:201-8.

[7] Halter F, Chauveau C, Gökalp I. Characterization of the effects of hydrogen addition in premixed methane/air flames. International Journal of Hydrogen Energy 2007;32:258592.

[8] Di Sarli V, Di Benedetto A. Laminar burning velocity of hydrogen-methane/air premixed flames. International Journal of Hydrogen Energy 2007;32:637-46. 
[9] Tahtouh T, Halter F, Samson E, Mounaïm-Rousselle C. Effects of hydrogen addition and nitrogen dilution on the laminar flame characteristics of premixed methane-air flames. International Journal of Hydrogen Energy 2009;34:8329-38.

[10] Boushaki T, Dhué Y, Selle L, Ferret B, Poinsot T. Effects of hydrogen and steam addition on laminar burning velocity of methane-air premixed flame: Experimental and numerical analysis. International Journal of Hydrogen Energy 2012;doi:10.1016/j.ijhydene.2012.03.037.

[11] Jackson GS, Sai R, Plaia JM, Boggs CM, Kiger KT. Influence of $\mathrm{H}_{2}$ on the response of lean premixed $\mathrm{CH}_{4}$ flames to high strained flows. Combustion and Flame 2003;132:503-11.

[12] Day M, Tachibana S, Bell J, Lijewski M, Beckner V, Cheng RK. A combined computational and experimental characterization of lean premixed turbulent low swirl laboratory flames I. Methane flames. Combustion and Flame 2012;159:275-90.

[13] Wicksall DM, Agrawal AK, Schefer RW, Keller JO. The interaction of flame and flow field in a lean premixed swirl-stabilized combustor operated on $\mathrm{H}_{2} / \mathrm{CH}_{4} /$ air. Proceedings of the Combustion Institute 2005;30:2875-83.

[14] Wicksall DM, Agrawal AK, Schefer RW, Keller JO. Influence of hydrogen addition on flow structure in confined swirling methane flames. Journal of Propulsion and Power 2005;21:16-24.

[15] Altay HM, Speth RL, Hudgins DE, Ghoniem AF. Flame-vortex interaction driven combustion dynamics in a backward-facing step combustor. Combustion and Flame 2009;156:1111-25. 
[16] Altay HM, Hudgins DE, Speth RL, Annaswamy AM, Ghoniem AF. Mitigation of thermoacoustic instability utilizing steady air injection near the flame anchoring zone. Combustion and Flame 2010;157:686-700.

[17] Kim KT, Lee JG, Lee HJ, Quay BD, Santavicca DA. Characterization of forced flame response of swirl-stabilized turbulent lean-premixed flames in a gas turbine combustor. Journal of Engineering for Gas Turbines and Power 2010;132:041502 (8 pages).

[18] Di Sarli V, Di Benedetto A, Russo G, Jarvis S, Long EJ, Hargrave GK. Large eddy simulation and PIV measurements of unsteady premixed flames accelerated by obstacles. Flow Turbulence and Combustion 2009;83:227-50.

[19] Gubba SR, Ibrahim SS, Malalasekera W, Masri AR. Measurements and LES calculations of turbulent premixed flame propagation past repeated obstacles. Combustion and Flame 2011;158:2465-81.

[20] Renard P-H, Thévenin D, Rolon JC, Candel S. Dynamics of flame/vortex interactions. Progress in Energy and Combustion Science 2000;26:225-82.

[21] Long EJ, Hargrave GK, Jarvis S, Justham T, Halliwell N. Characterisation of the interaction between toroidal vortex structures and flame front propagation. Journal of Physics: Conference Series 2006;45:104-11.

[22] Long EJ, Hargrave GK. Experimental measurement of local burning velocity within a rotating flow. Flow, Turbulence and Combustion 2011;86:455-76.

[23] Di Sarli V, Di Benedetto A, Russo G. Large eddy simulation of transient premixed flame-vortex interactions in gas explosions. Chemical Engineering Science 2012;71:53951. 
[24] Di Sarli V, Di Benedetto A. Sensitivity to the presence of the combustion sub-model for large eddy simulation of transient premixed flame-vortex interactions. Industrial \& Engineering Chemistry Research 2012;51:7704-7712.

[25] Kee RJ, Grcar JF, Smooke MD, Miller JA. A Fortran program for modeling steady Iaminar one-dimensional premixed flames, Sandia report SAND85-8240;1985.

[26] Smith GP, Golden DM, Frenklach M, Moriaty NW, Eiteneer B, Goldenberg M, et al. The "GRI-Mech 3.0" chemical kinetic mechanism, http://www.me.berkeley.edu/gri_mech; 1999 [accessed on 10.04.12].

[27] Di Benedetto A, Di Sarli V, Salzano E, Cammarota F, Russo G, Explosion behavior of $\mathrm{CH}_{4} / \mathrm{O}_{2} / \mathrm{N}_{2} / \mathrm{CO}_{2}$ and $\mathrm{H}_{2} / \mathrm{O}_{2} / \mathrm{N}_{2} / \mathrm{CO}_{2}$ mixtures. International Journal of Hydrogen Energy 2009;34:6970-8.

[28] Gaseq, A Chemical Equilibrium Program for Windows, http://www.c.morley.dsl.pipex.com/ [accessed on 10.04.12].

[29] Vasudeo N, Echekki T, Day MS, Bell JB. The regime diagram for premixed flame kernel-vortex interactions-Revisited. Physics of Fluids 2010;22:043602. 


\section{Table Captions}

Table 1 . Maximum rotational velocity of the vortex core, $u_{\theta, \max }$, laminar burning velocity, $S_{L}$, and $u_{\theta, \max } / S_{L}$ ratio for lean and stoichiometric mixtures with different with hydrogen mole fractions in the fuel (hydrogen plus methane), $x_{H 2}$

Table 2. Initial slope for flame area curves shown in Figures 7 and 8 


\section{Figure Captions}

Figure 1. Schematic representation of the combustion bomb (cylindrical pre-chamber: $35 \mathrm{~mm}$ in height and $70 \mathrm{~mm}$ in diameter; main chamber: $150 \mathrm{~mm}$ x $150 \mathrm{~mm}$ x $150 \mathrm{~mm}$; orifice: $25 \mathrm{~mm}$ in height and $30 \mathrm{~mm}$ in diameter, 90 degree corners at both the inlet and exit faces). Details of the image region location are also given.

Figure 2. Schematic of TRPIV layout.

Figure 3. Flame-vortex interactions for different hydrogen mole fractions in the fuel (lean mixtures): Temporal sequences of raw images of the laser illuminated particles gathered using the TRPIV technique.

Figure 4. Flame-vortex interactions for different hydrogen mole fractions in the fuel (stoichiometric mixtures): Temporal sequences of raw images of the laser illuminated particles gathered using the TRPIV technique.

Figure 5. TRPIV taken at $1500 \mathrm{~Hz}$ with a resolution of 1024 x 1024 pixels: Lean mixtures with $x_{H 2}$ equal to (a) 0 , (b) 0.2 , (c) 0.4 and (d) 0.5 .

Figure 6. TRPIV taken at $1500 \mathrm{~Hz}$ with a resolution of 1024 x 1024 pixels: Stoichiometric mixtures with $x_{H 2}$ equal to (a) 0 , (b) 0.2 , (c) 0.4 and (d) 0.5 . 
Figure 7. Temporal trends of flame surface area and burning rate: Lean mixtures with varying $x_{H 2}$.

Figure 8. Temporal trends of flame surface area and burning rate: Stoichiometric mixtures with varying $x_{H 2}$.

Figure 9. Spectral diagram of flame kernel-vortex interaction by Vasudeo et al. [29]: DNS results provide the boundaries between five distinct regimes (reverse triangles: laminar kernel regime; squares: wrinkled kernel regime; diamonds: breakthrough regime; triangles: global extinction regime; circles: RGE regime). The diagram includes the current results for hydrogen mole fraction in the fuel, $x_{H 2}$, varying in the range of $0-0.5$ (stars: lean mixtures; rectangles: stoichiometric mixtures; black symbols: pure methane; grey symbols: $x_{H 2}=0.2$; dark grey symbols: $x_{H 2}=0.4$; white symbols: $x_{H 2}=0.5$ ). 


\begin{tabular}{lccc}
\hline $\mathrm{X}_{\mathrm{H}_{2}}$ & $u_{\theta, \max }[\mathrm{m} / \mathrm{s}]$ & $\mathrm{S}_{L}{ }^{a}[\mathrm{~m} / \mathrm{s}]$ & $u_{\theta, \max } / S_{L}$ \\
\hline$\varphi=0.8$ & & & \\
0 & 9 & 0.29 & 31 \\
0.2 & 11 & 0.32 & 34.4 \\
0.4 & 15 & 0.38 & 39.5 \\
0.5 & 17 & 0.42 & 40.5 \\
$\varphi=1$ & & & \\
0 & 11 & 0.41 & 26.8 \\
0.2 & 13 & 0.45 & 28.9 \\
0.4 & 17 & 0.54 & 31.5 \\
0.5 & 20 & 0.61 & 32.8 \\
a CHEMKIN computations. & &
\end{tabular}

Table 1. 


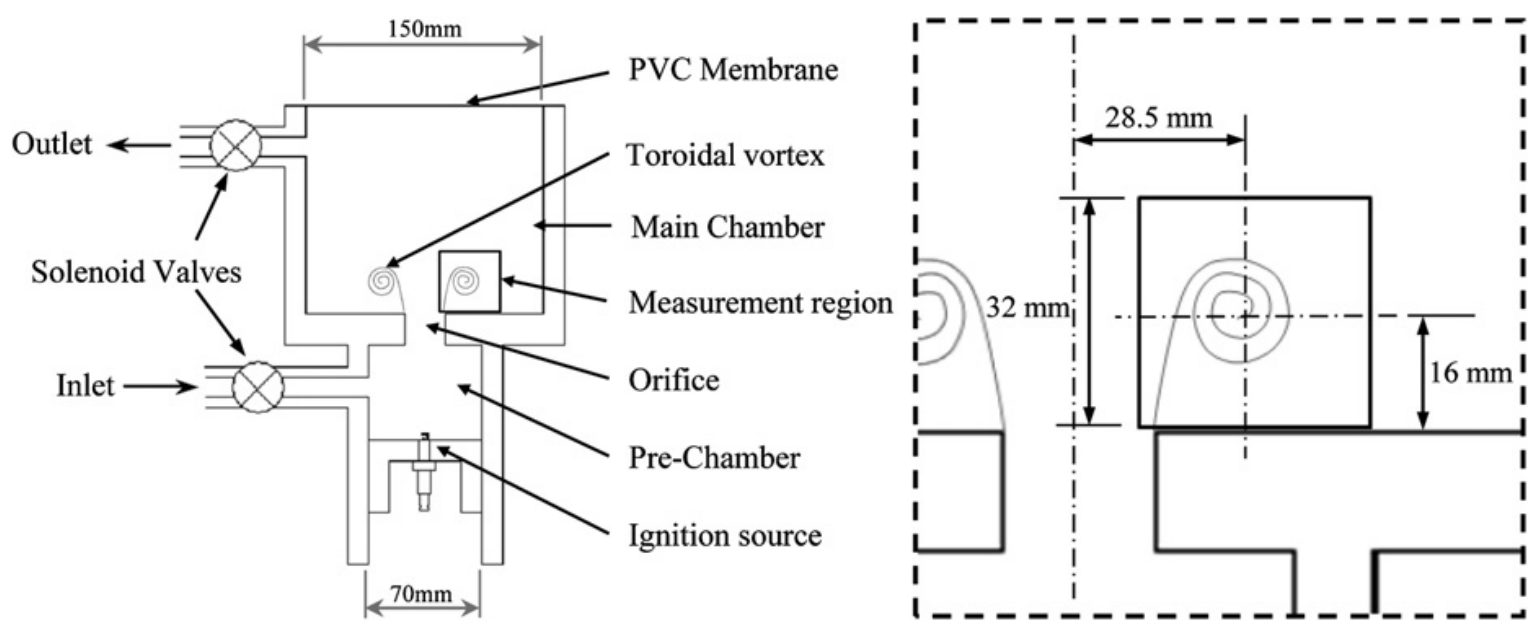

Figure 1. 


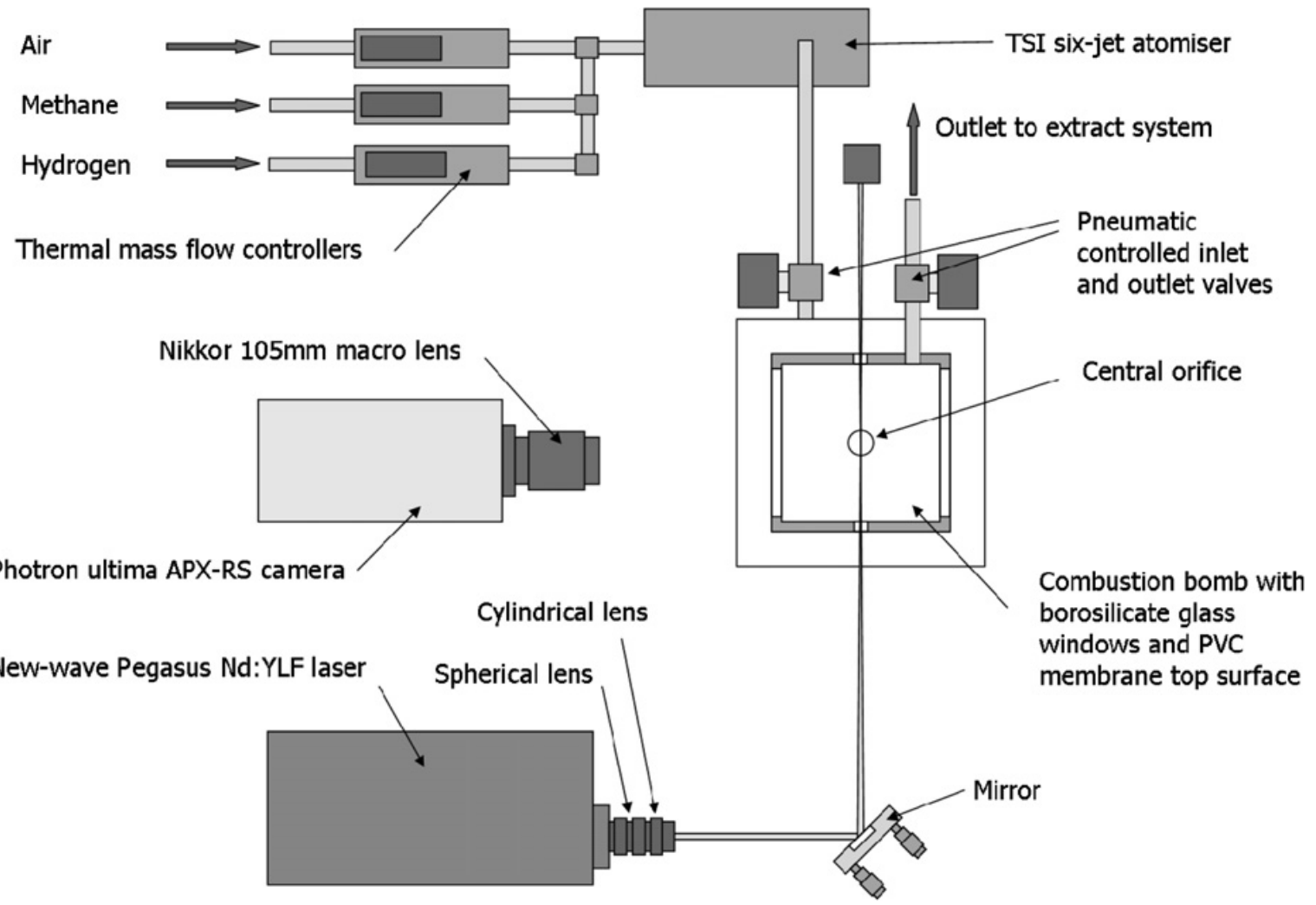

Figure 2. 


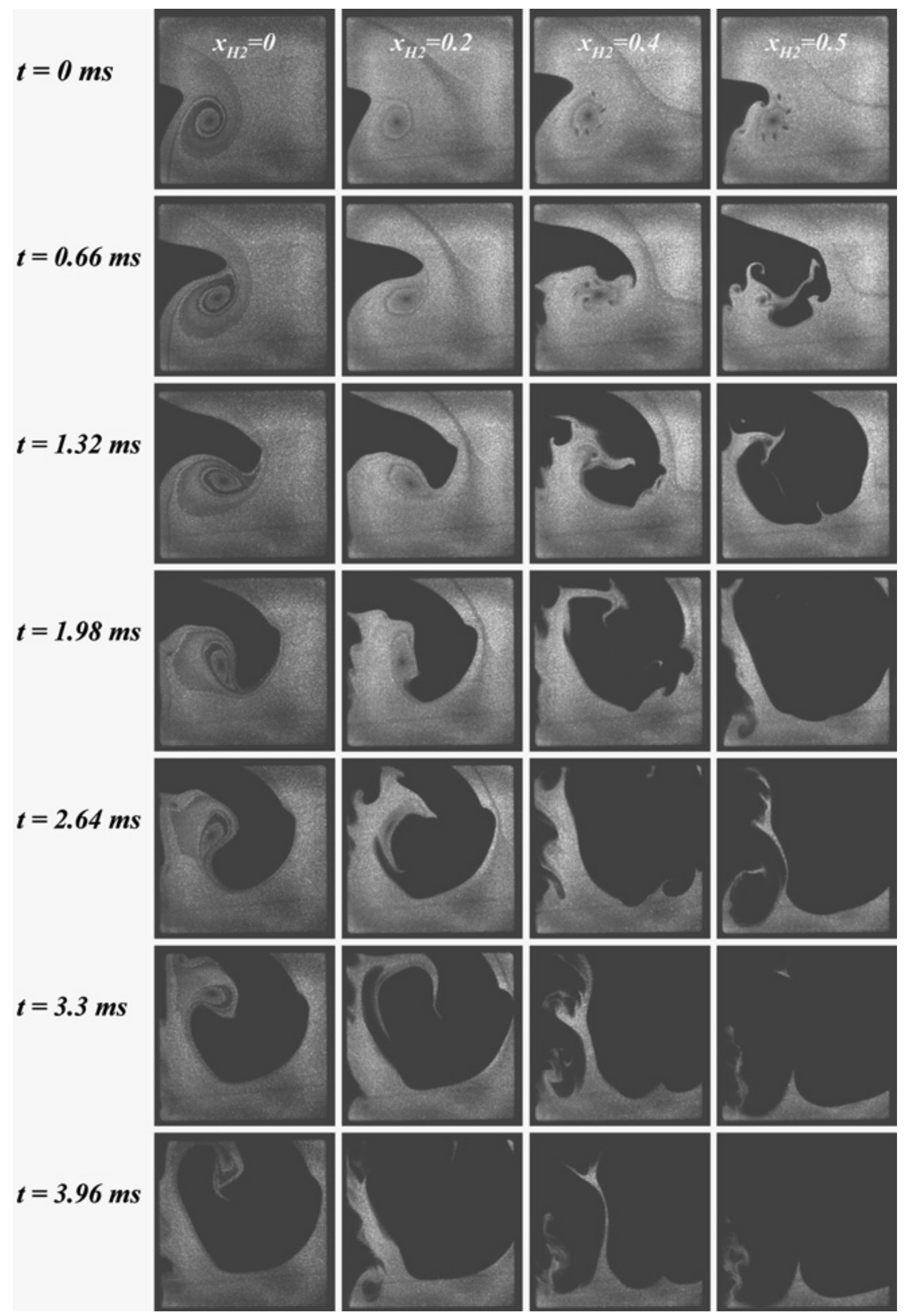

Figure 3. 


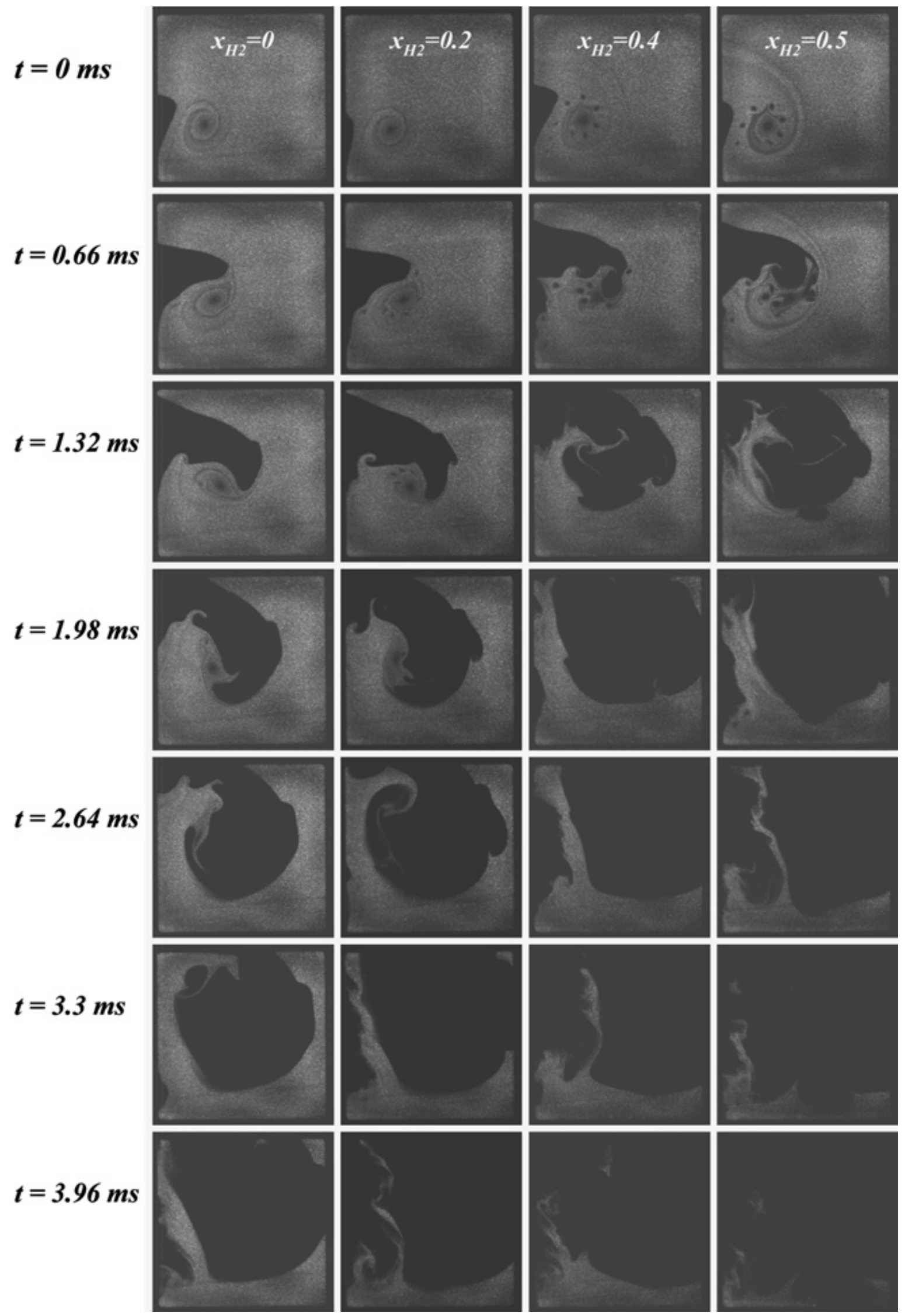

Figure 4. 

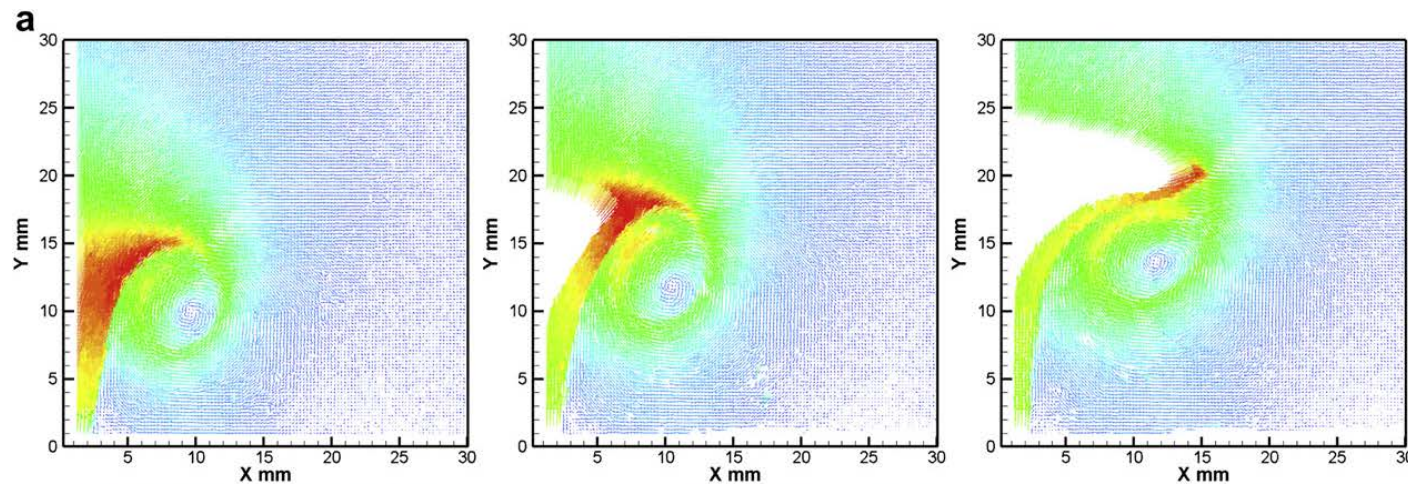

[m/s]
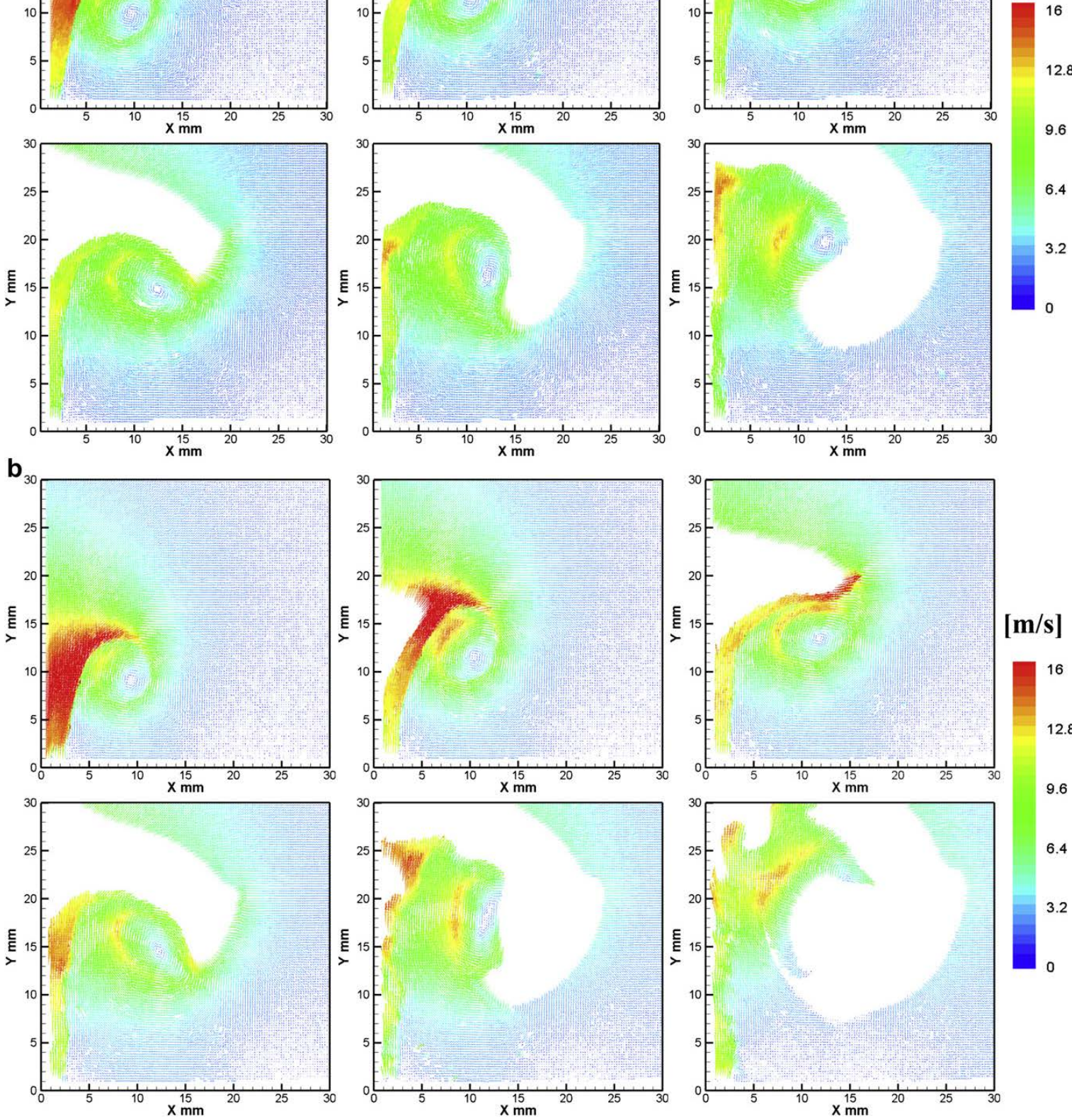

Figure 5. 

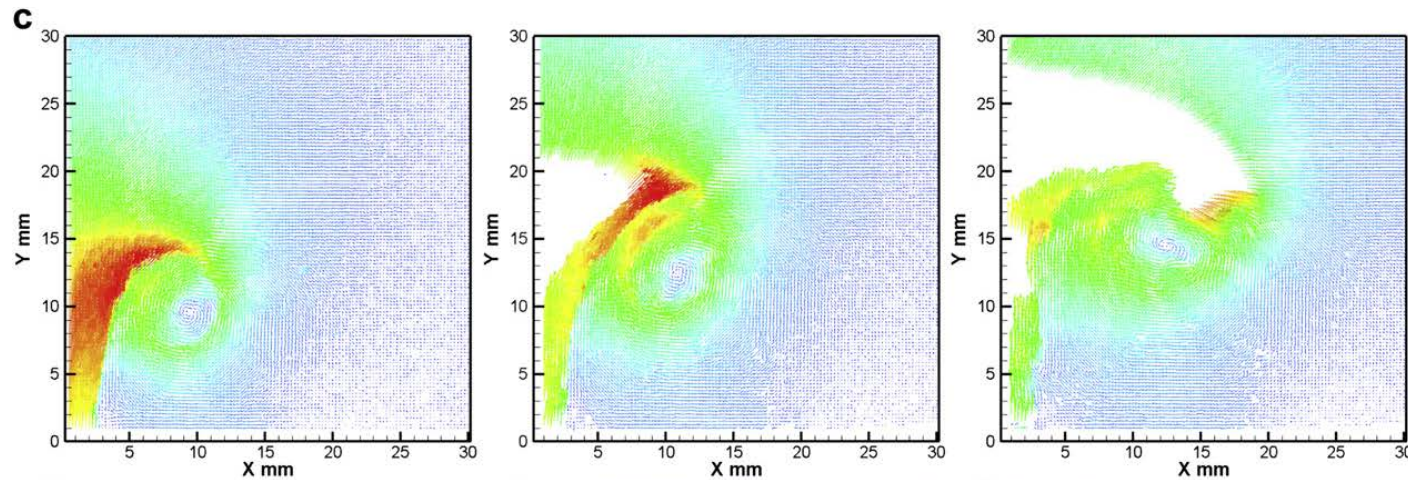

$[\mathrm{m} / \mathbf{s}]$
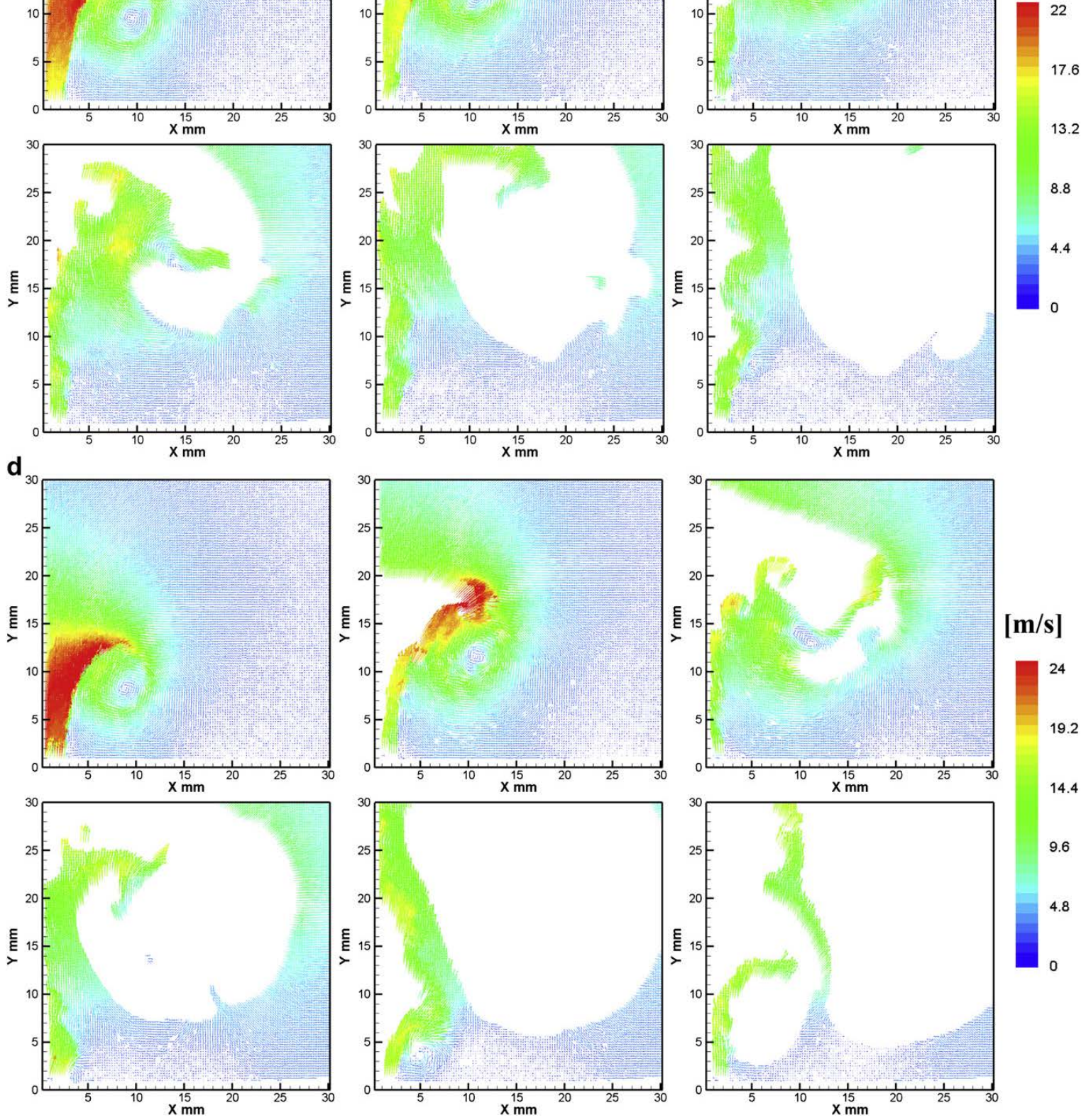

Figure 5 (continued) 

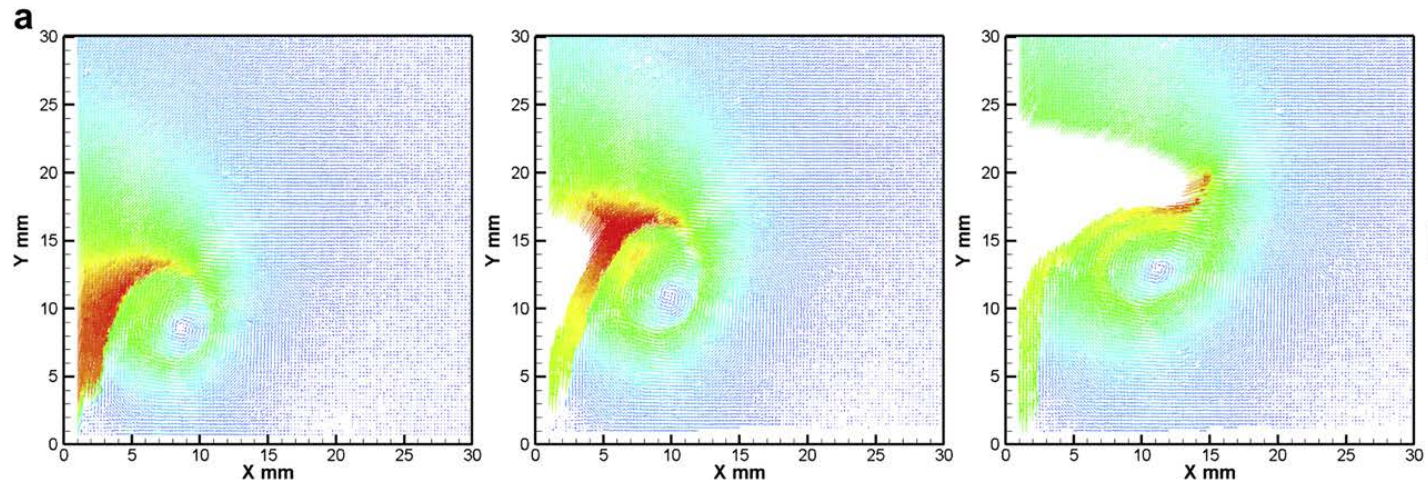

$[\mathrm{m} / \mathrm{s}]$
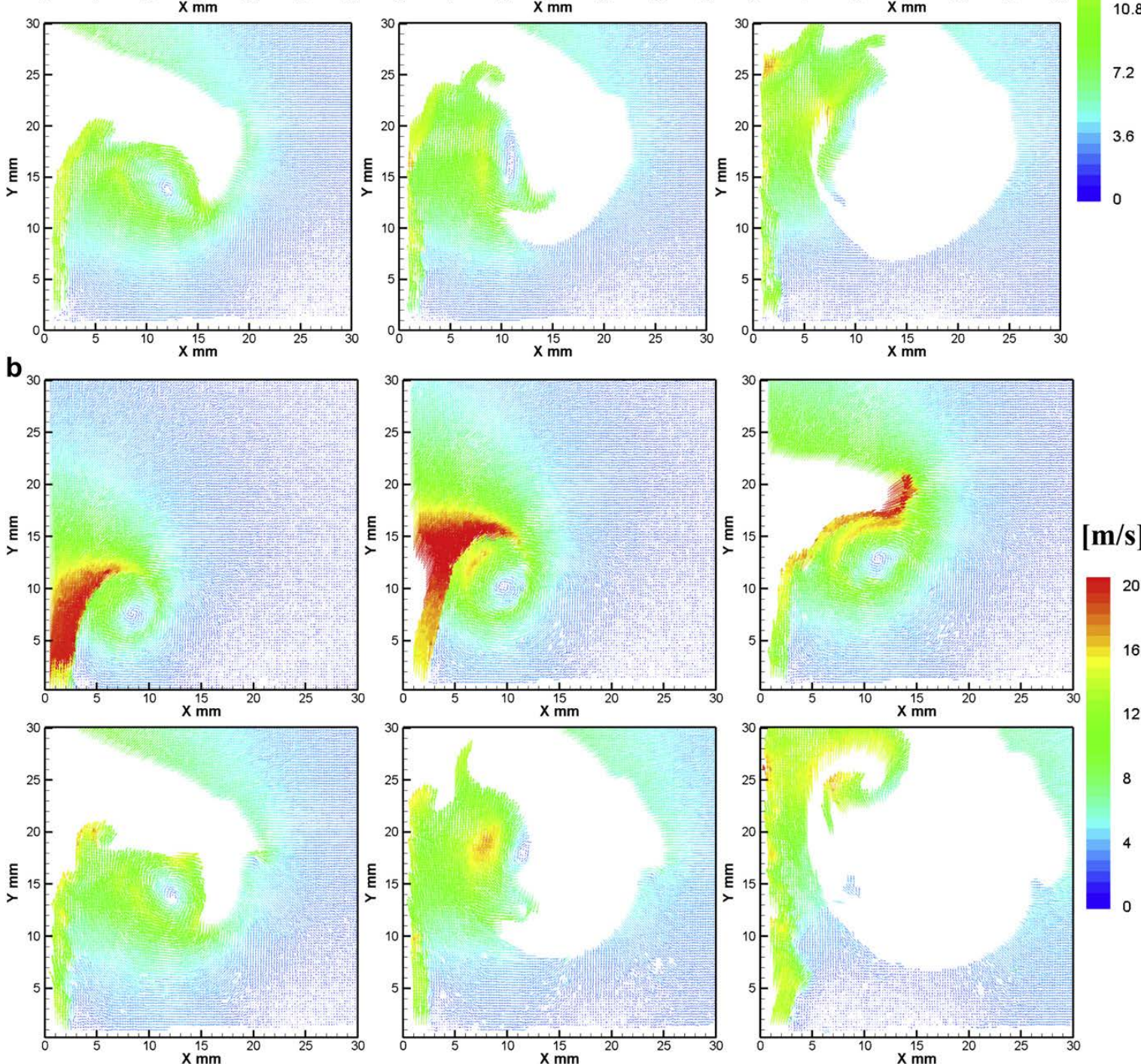

Figure 6. 

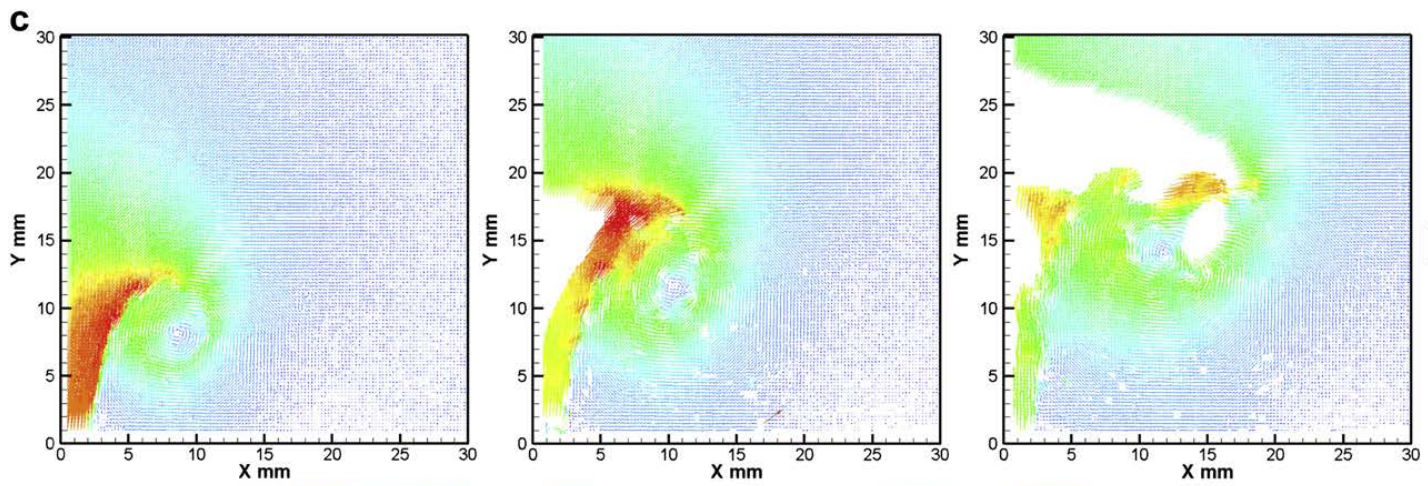

$[\mathrm{m} / \mathbf{s}]$
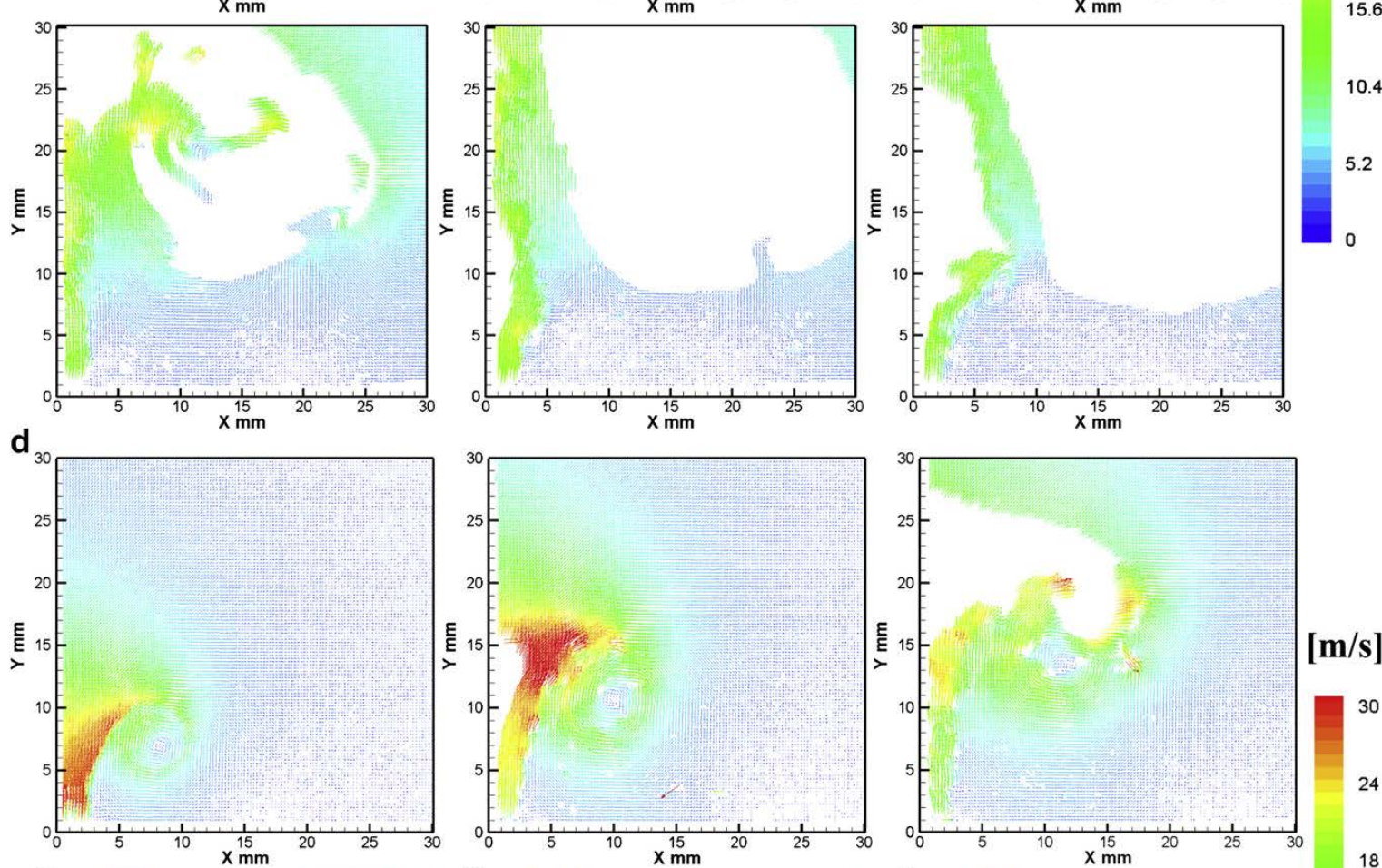

$[\mathbf{m} / \mathbf{s}]$
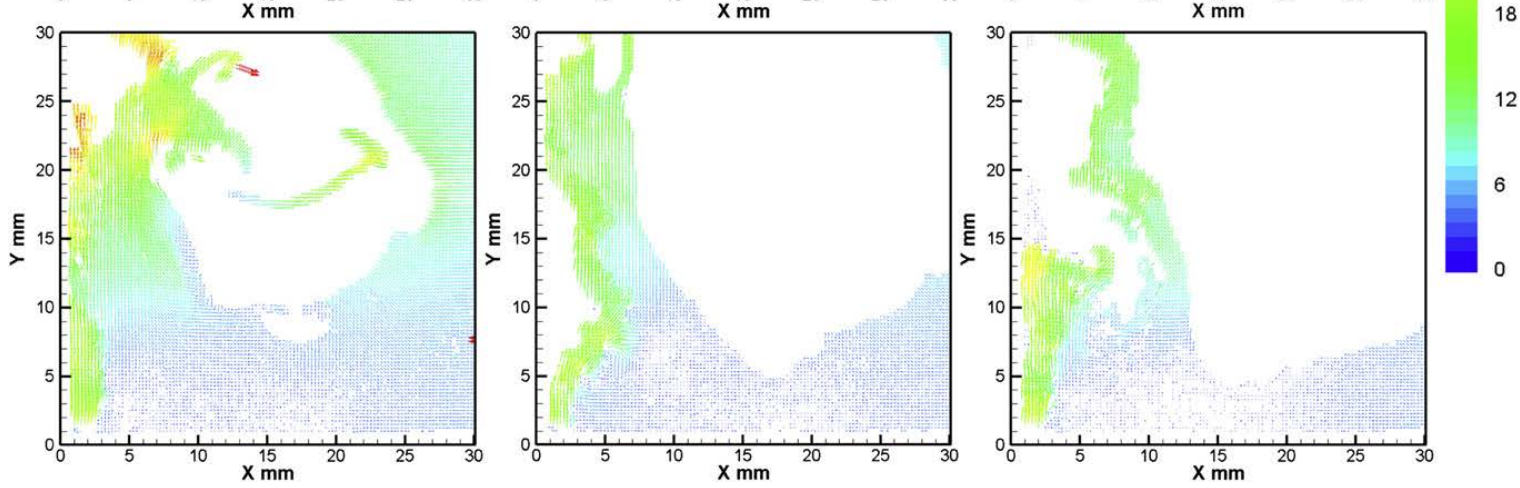

Figure 6 (continued) 

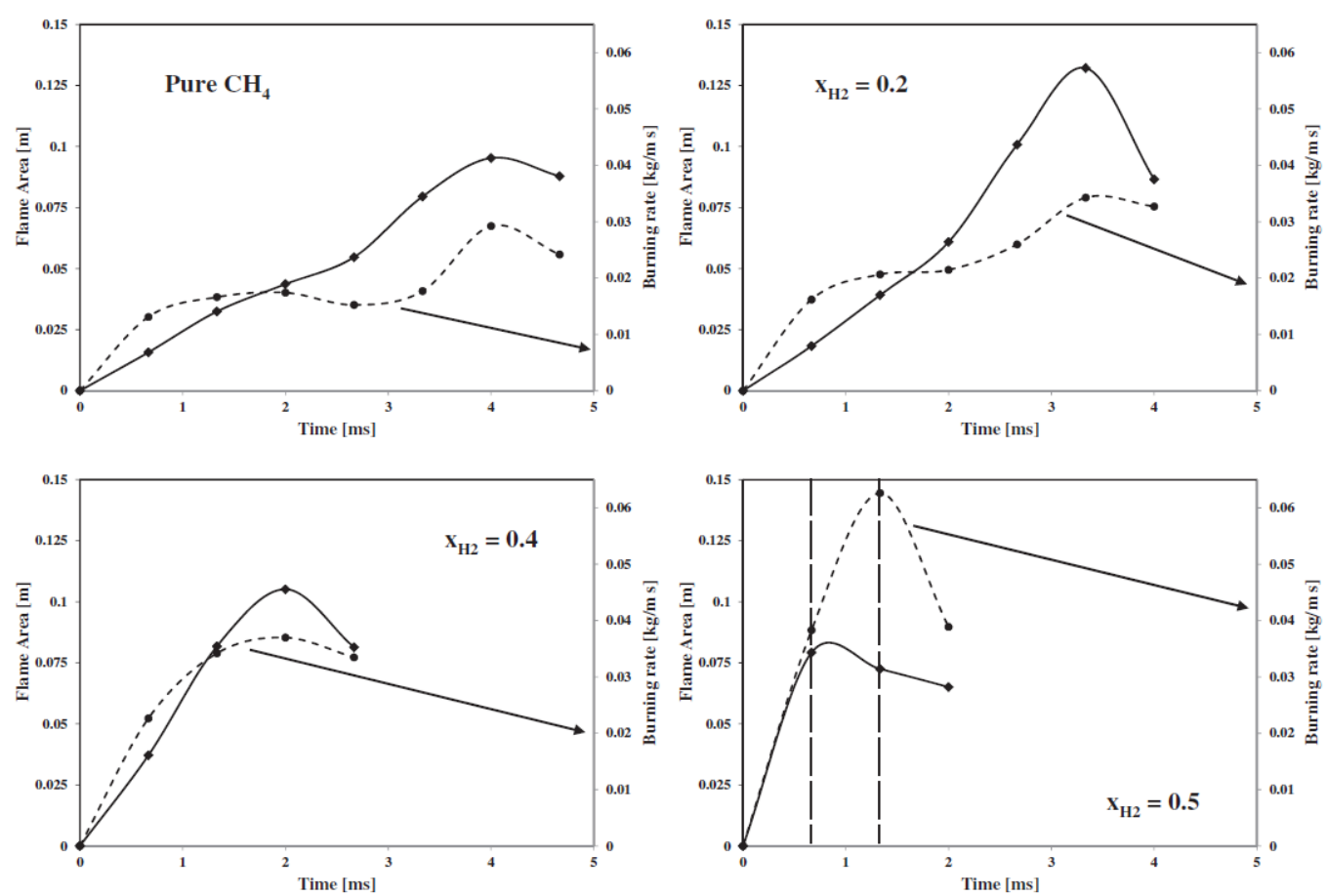

Figure 7. 

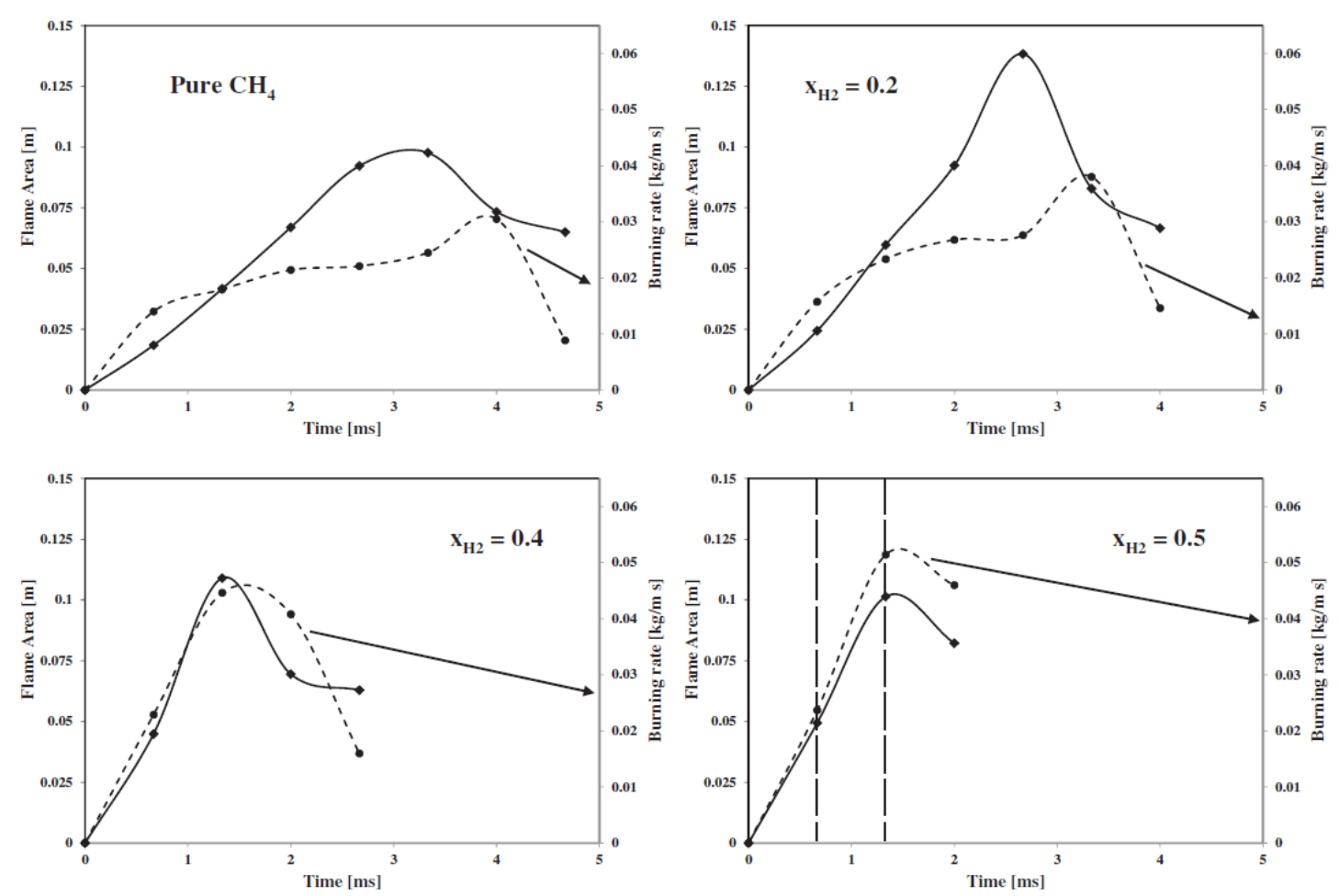

Figure 8. 


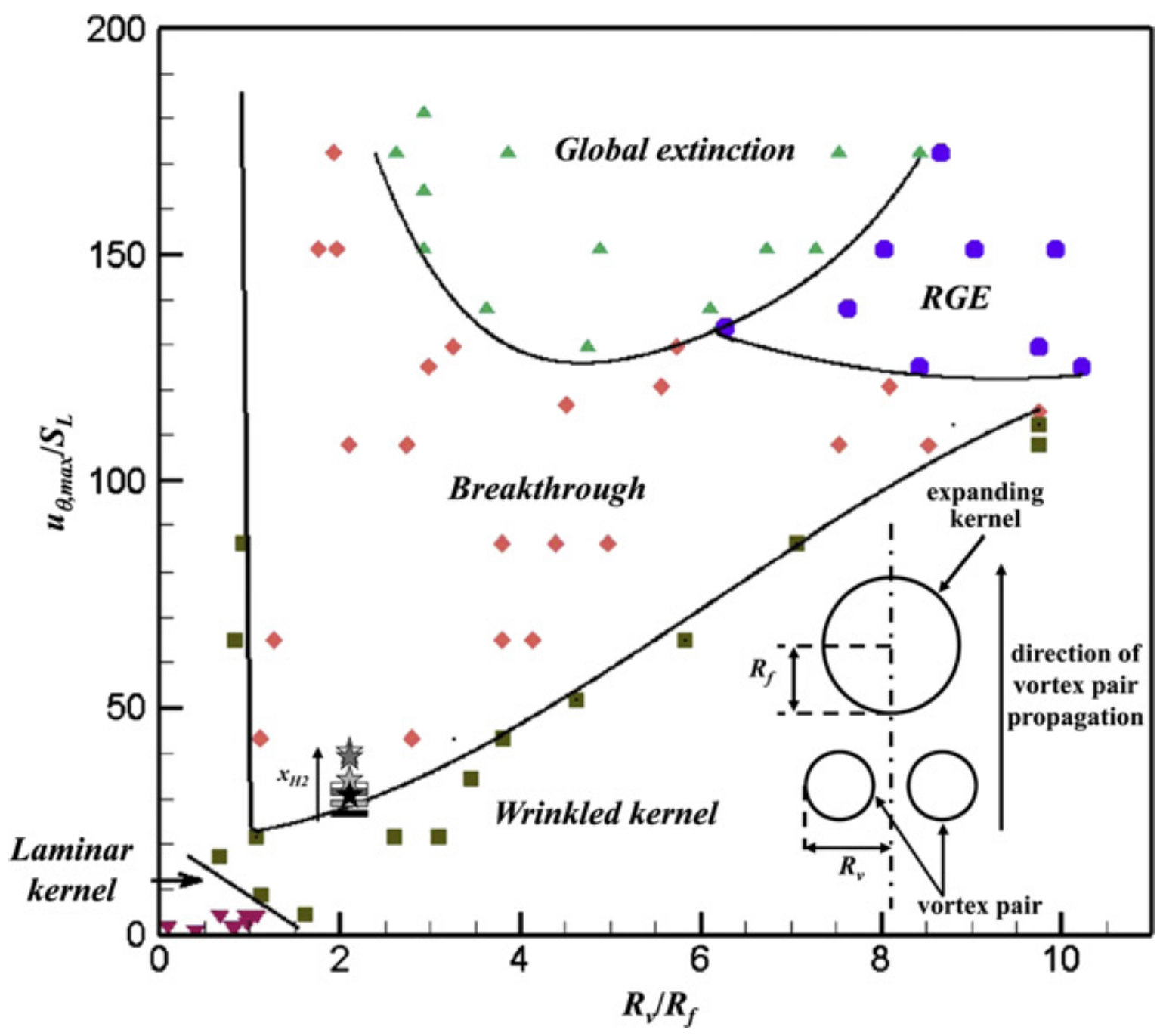

Figure 9. 
